Economic and Environmental Geology

Research Paper

\title{
Evaluation for Predicting Acid-forming Potential of Domestic Forest Aggregate Samples
}

\author{
Gil-Jae Yim ${ }^{1, *}$, Jeong-Yun Jang ${ }^{1,3}$, Dong-Wan $\mathrm{Cho}^{1}$, Sangwoo $\mathrm{Ji}^{1}$, Young Wook Cheong ${ }^{1}$, Sei-Sun Hong ${ }^{2}$, \\ Jin-Young Lee ${ }^{2}$ \\ ${ }^{1}$ Geologic Environment Division, Korea Institute of Geoscience and Mineral Resources, Daejeon, Korea \\ ${ }^{2}$ Geology Division, Korea Institute of Geoscience and Mineral Resources, Daejeon, Korea \\ ${ }^{3}$ Dept. of Earth Resources and Environmental Engineering, Hanyang University, Seoul, Korea \\ *Corresponding author : gjyim@kigam.re.kr
}

\section{ARTICLE INFORMATION}

Manuscript received 26 September 2021

Received in revised form 18 October 2021

Manuscript accepted 19 October 2021

Available online 29 October 2021

DOI : http://dx.doi.org/10.9719/EEG.2021.54.5.561

\section{Research Highlights}

- Some aggregate samples were classified as acid-forming potential aggregate.

- Aggregates containing aggregates capable of acid-forming potential can lead to structural stability and environmental pollution in the long run.

\begin{abstract}
Aggregate collection is taking place in many areas in Korea, resulting in large cut slopes or large amounts of cut rocks. If the development site for such aggregate collection is a stratum accompanied by sulfide minerals, Acid Rock Drainage (ARD) may occur, which may cause environmental pollution in the development site and surrounding areas. As a result of the study on forest aggregate samples, most of the samples were classified as acid-forming potential samples, and among them, some samples from Gwangju, Goyang, and Sokcho were classified as potential acid-generating samples. This can be expected to affect the quality of aggregates when a large amount of aggregate is used in the future. Therefore, it is judged that these forest aggregates need to be managed when they are used. By predicting the occurrence of ARD through the acid-generating ability test, it is expected that economic losses that may occur in the future can be reduced, and it is judged that the problem of surrounding environmental pollution can be further alleviated.
\end{abstract}

Keywords : forest aggregate, acid rock drainage, potentially acid forming(PAF), non-acid forming(NAF), sulfide mineral

Citation: Yim, G.-J., Jang, J.-Y., Cho, D.-W., Ji, S., Cheong, Y.W., Hong, S.-S., Lee, J,-Y. (2021) Evaluation for Predicting Acidforming Potential of Domestic Forest Aggregate Samples. Korea Economic and Environmental Geology, v.54, p.561-572, doi:10.9719/EEG2021.54.5.561.

This is an Open Access article distributed under the terms of the Creative Commons Attribution Non-Commercial License (http://creativecommons.org/ licenses/by-nc/3.0) which permits unrestricted non-commercial use, distribution, and reproduction in any medium, provided original work is properly cited. pISSN 1225-7281; eISSN 2288-7962/C2021 The KSEEG. Printed by Hanrimwon Publishing Company. All rights reserved. 


\section{연구논문}

\section{국내 산림골재 시료의 산성암석배수 발생 가능성 예측 평가}

임길재 ${ }^{1, *} \cdot$ 장정윤 $^{1,3} \cdot$ 조동완 $^{1} \cdot$ 지상우 $^{1} \cdot$ 정영욱 $^{1} \cdot$ 홍세선 $^{2} \cdot$ 이진영 $^{2}$

${ }^{1}$ 한국지질자원연구원 지질환경연구본부

2한국지질자원연구원 국토지질연구본부

3한양대학교 자원환경공학과

*책임저자 : gjyim@kigam.re.kr

\section{요 약}

국내의 많은 지역에서 골재 채취가 이루어지고 있으며 이로 인해 대형 절토사면이나 다량의 절취된 암석이 발생되고 있다. 이 러한 골재 채취를 위한 개발부지가 황화광물이 수반된 지층일 경우 산성암석배수(Acid Rock Drainage : ARD)가 발생하여 개발 부지 내와 주변지역에 환경오염의 문제를 발생시킬 수 있다. 산림골재 시료를 대상으로한 연구결과 시료 대부분이 잠재적인 비 산발생 시료로 분류되고 그중에 광주시, 고양시, 속초시의 일부 시료에서 잠재적인 산발생 시료로 분류되어지는 결과를 얻었다. 이는 향후 다량의 골재가 사용될 경우 골재의 품질에 영향을 줄 수 있음을 예상할 수 있다. 따라서 이러한 산림골재들은 사용 시 관리가 필요할 것으로 판단된다. 산 발생 능력 시험을 통한 $\mathrm{ARD}$ 발생 예측으로, 향후 발생 될 수 있는 경제적 손실을 줄일 수 있을 것으로 기대되며, 주변 환경오염 문제를 보다 완화 시킬 수 있을 것으로 판단된다.

주요어 : 산림골재, 산성암석배수, 산발생, 비산발생, 황화광물

\section{1. 서 론}

골재는 필수적인 건설자재로 하천, 해양, 산림, 육상 골 재로 분류되는데 산림골재의 경우 1988년부터 2010년까 지 채취실적이 14 억 5 천백만 $\mathrm{m}^{3}$ 이상을 사용하고 있으며 (Fig. 1), 이러한 산림골재는 천연자원으로 각 시군에 따 라 부존특성이 다르며, 골재자체의 사용물량과 그 중량 으로 인해 원거리에서 조달이 힘들다는 특성이 있다. 또 한 골재를 대체할 만한 대체재를 개발하기가 쉽지 않은

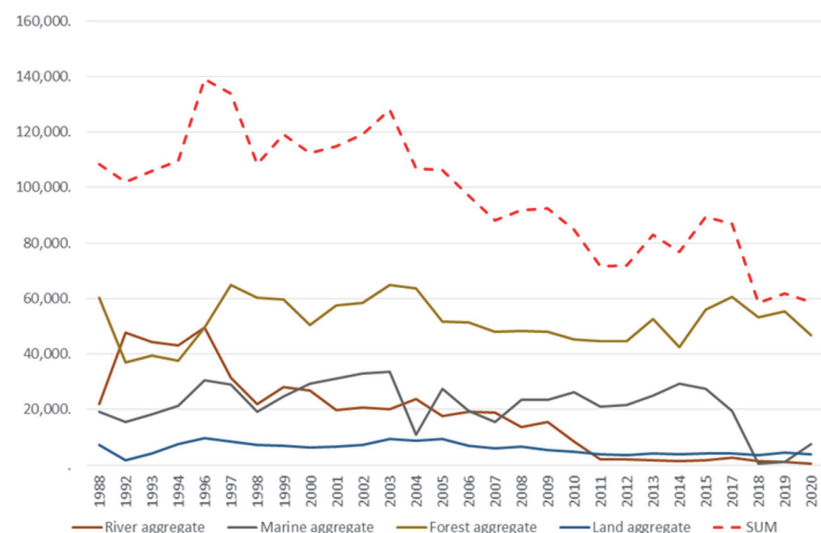

Fig. 1. The amount of aggregates quarried in Korea (MOLIT, 2021, UNIT : thousand $\mathrm{m}^{3}$ ).
특성을 가지고 있다.

골재의 채취는 국내의 많은 지역에서 발생한다. 이로 인해 대형 절토사면이나 다량의 절취된 암석이 발생되고 있다. 이렇세 개발된 부지가 황화광물이 수반된 지층일 경우 산성암석배수(Acid Rock Drainage : ARD)가 발생 하여 환경오염 혹은 구조물에 대한 부식 등의 문제를 발 생시킬 수 있다. 일반적으로 산성암석배수(Acid Rock Drainage, ARD)는 광산 지역에서 많이 발생되어 광산지 역에 국한된 문제로만 인식되어져 왔으나, 최근에 $\mathrm{ARD}$ 는 공항 및 도로 건설, 채석장, 벌목장 등 토목건설공사 가 황화광물을 수반한 지층 및 광산 관련지역을 통과할 경우 빈번히 발생하고 있다. 이러한 $\mathrm{ARD}$ 에 의한 영향은 $\mathrm{pH}$ 가 낮은 산성수에 중금속이 포함되어서 심각한 환경 오염 문제를 야기시키고 또한 황산염 등이 고농도로 함 유되어 주변지역의 콘크리트 부식, 황산염 팽창에 의한 구조물 바닥의 균열 발생과 절개지에서 사면 불안정 등 의 공학적인 피해를 초래할 수도 있다(Orndorff, 2001; Lee et al., 2005 a,b). 어떤 지층의 잠재 산도(Potential acidity)는 지층을 구성하는 구성광물에 우선적으로 지배 되기 때문에 지질 고유특성에 따라서 산 발생 가능성이 결정된다(Carrucio, et al., 1977, Skousen, et al., 1997).

국내의 일부 지역 암석에 대한 산 발생 예측 시험결과 를 살펴보면 삼척탄좌 폐석장 셰일, 무주 고속도로변 절 

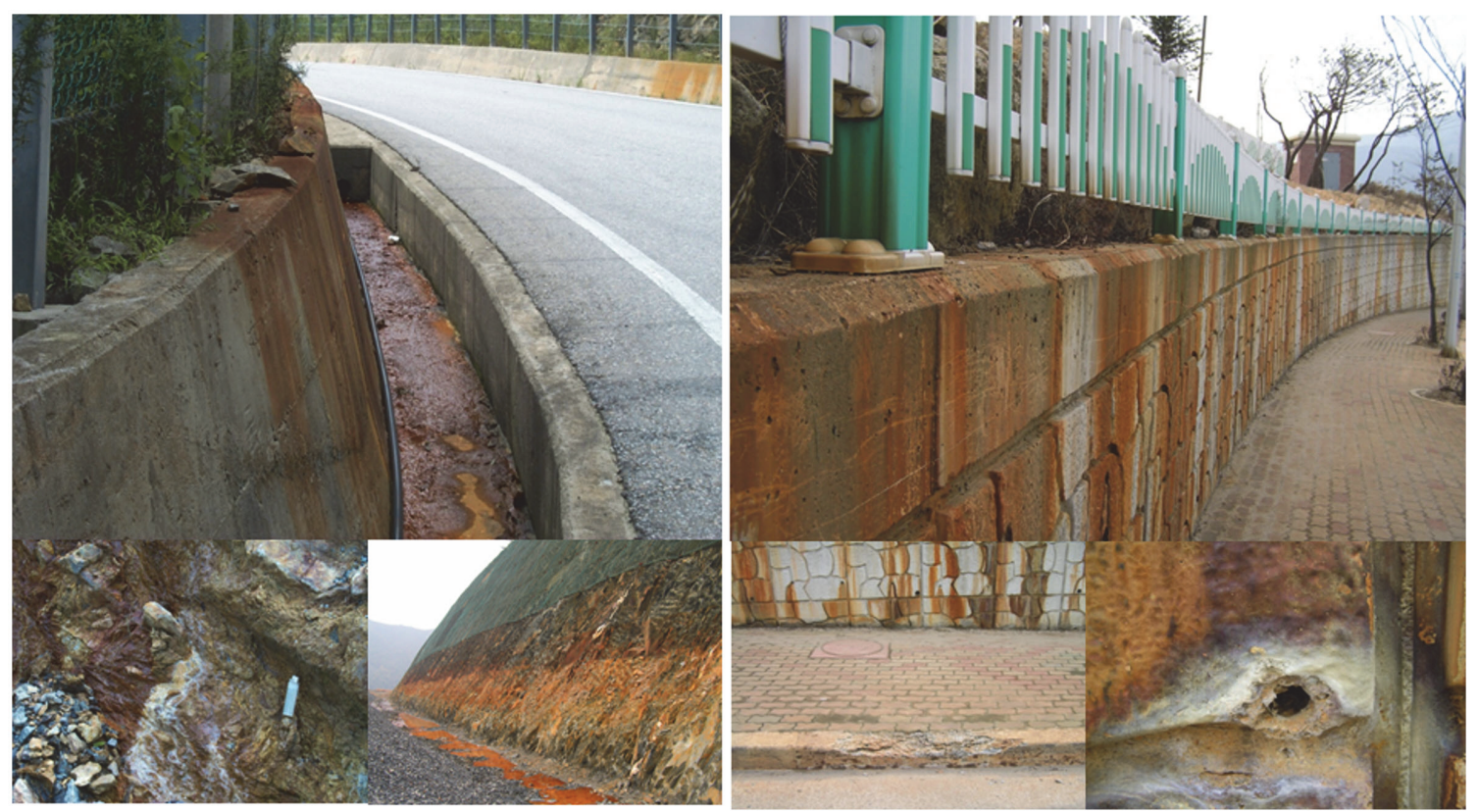

Fig. 2. Damage caused by ARD at civil construction sites (left) and residential areas where ARD has occurred (right).

개지 셰일, 보은지역 지방도 절개지의 천매암의 경우 각 각 최대 $328 \mathrm{~kg} \mathrm{CaCO}_{3} /$ ton, $102.8 \mathrm{~kg} \mathrm{CaCO}_{3} / \mathrm{ton}, 50.9 \mathrm{~kg}$ $\mathrm{CaCO}_{3} / \mathrm{ton}$ 의 잠재 산도를 갖는 것으로 평가된 바 있다 $(\mathrm{Ji}$ \& Cheong, 2005). 이러한 ARD 발생 잠재력을 갖는 암 석들은 지표면에 절개지 형태 혹은 폐석 등으로 지표환 경에 노출되면 중금속으로 오염된 $\mathrm{ARD}$ 가 유출되어 주 변 환경을 오염시킬 수 있다.

최근에 국내에서도 터널, 도로 절취사면 등에서 $\mathrm{ARD}$ 의 발생에 의한 환경오염 문제들이 보고되면서(Ji \& Cheong, 2005, Lee et al., 2005 a,b, Yim et al., 2006) ARD 발생 에 대한 사전 평가 필요성이 대두되고 있다(Fig. 2). Lee et al.(2005 b)이 보고한 $\mathrm{ARD}$ 에 의한 절취사면 구조물의 피해 현황 및 평가에서 $\mathrm{ARD}$ 는 사면구조물에 악영향을 미치고 숏크리트의 열화현상을 유발하며 식생공의 경우 씨앗의 발아와 성장에 악영향을 미친다고 보고한 바 있 다. 현재 우리나라는 신도시 건설 및 도로건설 등이 지 속적으로 추진되고 있어서 지질조건에 따라서 향후 $\mathrm{ARD}$ 문제가 지속적으로 발생할 가능성이 있다.

골재채취 현장에서의 $\mathrm{ARD}$ 의 문제는 대부분 어느 정 도 진행된 후 발생되며, 발생된 이후 처리에는 많은 비 용이 소요되어 해결에 많은 어려움이 따른다. 따라서 골 재 등의 암석 채취 설계시부터 황화광물에 의한 $\mathrm{ARD}$ 의 발생을 사전 예측 조사하여 적절한 대책을 마련하는 것 이 바람직할 것이다. $\mathrm{ARD}$ 를 발생할 수 있는 암석을 사 전에 판별할 수 있는 방법들로는 Acid Base Accounting (ABA), Modified ABA procedures, Carbonate Neutralization
Potential determinations, Humidity cell tests, Column tests, Batch reactor (Shake flask) tests, Field test 등 여러 가지 방법들이 연구되어 왔다(Orava, 1997; USEPA and Hardrock Mining, 2003). 이러한 방법들은 광산개발과정 에서 발생되는 황화광물을 함유하는 폐석에 대해 적용되 어 온 방법들이었으나, 건설공사에 까지 적용이 확대되 고 있다(Surface Mine Drainage Task Force, 1979; Sobek, et al., 2000). 이러한 ARD 평가방법의 건설공사 분야에 대한 적용은 국내에서도 다양하게 시도되고 있다(Ji \& Cheong, 2005; Lee et al., 2006; Yim et al., 2006; Ji et al., 2006; Ji rt al., 2007; Kim et al., 2008). 본 논문에서는 산림골재 $\mathrm{ARD}$ 의 발생 예측을 통해 골재채취시 문제점 을 검토하여 $\mathrm{ARD}$ 의 환경적 영향과 발생 예측의 중요성 을 제시하고자 하였다.

\section{2. 연구 대상 지역}

연구에 사용한 산림골재들은 산성암석배수 발생가능성 을 평가하기 위하여 6 개 시군지역에서 채취된 암석시료 를 대상으로 하여 수행하였다. 시료 채취지역의 선정은 행정구역을 기반으로 지질을 고려하여 대상지역에 나타 나는 노두를 기준으로 채취하였다. 따라서 지역별로 지 질의 다양성과 범위의 차이로 인하여 분석된 시료의 수 가 일정하지 않다. 채취된 시료의 개수는 고양시 11 개, 가평군 16 개, 속초시 7 개, 광주시 15 개, 괴산군 19 개, 합천 군 25 개로 총 93 개의 산림골재 시료가 사용되었다. 
연구 대상 지역의 개괄적인 지질을 살펴보면 다음과 같다. 고양시 일대의 지질은 선캠브리아기 변성암류인 경기 편마암복합체가 넓게 저지대에 분포하고 있으며, 북동-남 서방향을 경계로 중생대 쥐라기 화강암류(흑운모화강암, 맥암류 등)가 관입하고 있다. 가평군은 층서 불분명의 고 원생대 편마암복합체가 대부분을 차지하며, 서부(조종면, 상면)에 쥐라기 화강암이 일부 분포한다. 고원생대 편마 암복합체 대부분은 흑운모편마암이 주를 이루며, 일부 지 역에서는 미그마타이트질 흑운모편마암 또는 호상 흑운 포편마암이 발달하기도 한다. 속초시는 남동부 지역에 트 라이아스기 복운모화강암, 양양섬장암과 양양화강암이 분 포하고, 서부와 북부에는 백악기 세존봉응회암, 속초화강 암, 설악산화강암, 화강섬록반암과 석영장석반암이 분포 하고 있다. 경기도 광주시의 최하부는 선캄브리아 시대 의 편암 및 편마암류(호상편마암, 우백질편마암 그리고 함석류석편마암)로 구성되어 있으며 선캄브리아 편암 및 편마암류는 이후 고원생대 반상변정 편마암에 의해 관입 을 당한다. 고원생대 반상변정 편마암의 관입 이후 쥐라 기 화강암이 선캄브리아 편암 및 편마암류와 고원생대 반상변정 편마암을 관입하였다.

괴산군에서는 층서적으로 최하부에 흔히 "함력 천매암 류”로 분류되었던 지층이 있으며, 이는 옥천누층군 상부 에 해당하는 신원생대 퇴적층인 황강리층-명오리층-서창 리층이다. 옥천누층군 상부 퇴적층은 칠성면과 장연면에 주로 분포하고 있으며, 주요 암상은 이질 또는 석회질 기 질을 가지는 함력천매암이다. 옥천누층군 상부 위로는 고 생대 중기에 해당하는 대향산규암, 운교리층이 퇴적되어 있다. 이들 쇄설성 변성퇴적암은 청안면과 문광면에 넓 게 분포하고 있으며, 비봉층을 포함한 변성퇴적층이 청 천면에 넓게 분포하고 있다. 쥐라기 화강암은 북부 사리 면에서 소수면을 거쳐 감물면 일대까지 넓게 분포한다. 백악기 화강암은 남부 청천면에서 연풍면 일대에 걸쳐 분포하고 있다. 백악기 중성 및 염기성 화산암류는 남부 청천면 일대에 소규모로 분포하고 있다.

합천군 일대의 지질은 북서부 가야산 일대는 화강편마 암이 현저하나, 동남부 일대는 중생대 경상계 낙동통의 지층으로 혈암·이암·사암·역암 등의 지층이 나타나고 있 다. 고기편마암류 및 이를 관입한 편상화성암류, 그리고 이 양자를 부정합으로 덮는 상부 중생대층들 및 이를 관 입한 불국사화성암류로 나뉜다. 선캠브리아기에 속하는 편마암류를 기반암으로 이와 관입관계를 이루는 시대미 상의 편상화성암류, 이를 백악기 경상누층군의 여러 퇴 적암류화산암류들이 부정합 관계를 이루며 관찰된다. 이 후 하부층들을 관입한 불국사 화성암류와 산성암맥과 중 성암맥이 분포하며 이들 모두를 계곡 및 하천을 따라서
제4기의 충적층이 이들을 부정합으로 덮고 있다(KIGAM, 2019).

\section{3. 연구 방법}

시료의 ARD 발생량을 평가하기 위한 방법은 1970년 대 이후 지속적으로 연구되어 오고 있다. 이러한 평가기 법들은 시험에 사용되는 화학약품 및 반응온도, 반응시 간 등에 있어 다소 차이를 보이나 암석시료가 가진 최대 $\mathrm{ARD}$ 발생능과 산중화능을 물리화학적인 시험방법을 통 해 강제적으로 구현해내고 이를 이용해 산발생량 $(=$ 산발 생능-산중화능)을 계산한다는 점에서 서로 유사성이 있다.

현재까지 암석시료의 $\mathrm{ARD}$ 발생량을 평가하기 위해 국 내외에서 주로 사용하는 평가기법은 $\mathrm{ABA}$ (Sobec et al., 1978) 시험과 NAG (Net Acid Generation) (Miler et al., 1997 ) 시험을 병행하여 그 결과를 동시에 고려하는 방법 이다. $\mathrm{ABA}$ 시험은 Total S 와 산 중화능력(ANC: Acid Neutralising Capacity) 시험으로 구성된다. 각각은 산발생 능과 산중화능을 도출하는 시험으로 두 결과의 차를 통 해 산발생량을 예측할 수 있다. 순 산발생 능력은 총 황 함량을 이용한 Maximum Potential Acidity (MPA)와 Acid Neutralization Potential (ANC)을 이용하여 두 값의 차이 를 통해 구한 산발생량은 NAPP (Net Acid Producing Potential)로 불리며 0 보다 큰 경우 산을 발생, 0 보다 작 은 경우 산을 발생하지 않는 시료로 분류된다. NAG는 $\mathrm{H}_{2} \mathrm{O}_{2}$ 를 이용하여 암석내 황철석을 모두 산화시켰을때 발 생하는 황산 동량(equivalent $\mathrm{kg} \mathrm{H}_{2} \mathrm{SO}_{4} / \mathrm{t}$ )을 구한 값으로 시험 특성상 산발생능과 산중화능이 모두 고려된 산발생 량을 직접 구할 수 있다. 또한 NAG pH 값은 산발생량을 직접적으로 의미하진 않지만 산발생의 여부를 간접적으로 판단할 수 있는 지표로 볼 수 있다. $\mathrm{pH} 4.5$ 를 기준으로

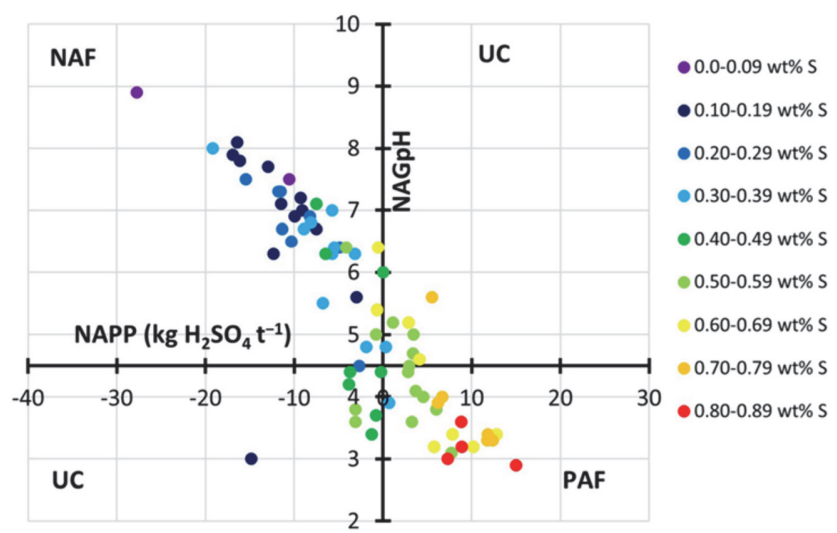

Fig. 3. Example of ARD evalution using acid forming potential evaluation method(Gerson et al., 2019). 
$\mathrm{NAG} \mathrm{pH}$ 가 이보다 작은 경우 산을 발생하는 시료로, 4.5 보다 큰 경우 산을 발생하지 않는 시료로 분류된다. $\mathrm{ABA}$ 시험에서 구한 NAPP와 NAG 시험에서 구한 NAG pH를 함께 고려하여 시료의 산발생 여부를 평가할 수 있다.

Fig. 3는 ARD 발생량 평가기법을 통해 암석시료의 $\mathrm{ARD}$ 발생량을 평가한 사례이다. 위 그래프에서 제 4 사 분면은 $\mathrm{ABA}$ 시험, $\mathrm{NAG}$ 시험에서 모두 산이 발생하는 것을 의미하는 영역으로 잠재적 산 발생(PAF; Potentially Acid Forming) 군으로 분류된다. 제 2 사분면은 두 시험 에서 모두 산이 발생하지 않는 것을 의미하며 산 비발생 (NAF; Non-Acid Forming) 군으로 분류된다. 다만, 제 1, 3 사분면에 존재하는 시료는 두 시험결과가 서로 상이한 경우이며 불확실(UC; Uncertain) 군으로 분류된다. 불확 실 시료이므로 필요시 추가 시험을 수행하기도 한다 (KIGAM, 2014).

\section{1. 시료준비 및 XRD 분석}

현장에서 채취한 시료는 200 번 체 이하로 $(<75 \mu \mathrm{m})$ 파 분쇄, 풍건조 등의 과정을 통해 시험에 적합하게 전처리 하여 준비한다. 그리고 구성광물을 감정하기 위해서 전 처리된 암석분말 시료에 대하여 XRD 분석(Phillips X'pert $\mathrm{MPD})$ 을 수행하였다.

\section{2. 황분석 및 $\mathrm{ANC}$ 시험}

Total S 시험은 시료 내 포함된 총 황 함량을 구하여 이를 모두 황철석으로 가정한 후 발생 가능한 최대 산발 생능을 계산하는 과정이다. ANC 시험은 산중화능을 구 하기 위한 시험으로 농도와 부피를 아는 산을 시료와 반 응시킨다. 이때 산과 탄산염의 반응으로 발생하는 $\mathrm{CO}_{2}$ 의 양을 통해 탄산염 함량을 대략적으로 파악하여 산의 투 입량을 결정하는 Fizz 시험을 수행하였다(Table 1).

Fizz 시험의 기포발생 등급에 따라 염산의 농도 및 부 피를 결정한다. 정확하게 산중화능을 평가하기 위해서는
Table 1. "Fizz Ratings" and Associated Acid Quantities and Concentrations to be used in the ANC Determination (AMIRA International, 2002)

\begin{tabular}{lcccc}
\hline \multirow{2}{*}{ Reaction } & Fizz & \multicolumn{2}{c}{$\mathrm{HCl}$} & $\begin{array}{c}\text { NaOH } \\
\text { Rating }\end{array}$ \\
\cline { 3 - 4 } & $\begin{array}{c}\text { Molarity } \\
(\mathrm{M})\end{array}$ & $\begin{array}{c}\text { Vol. } \\
(\mathrm{ml})\end{array}$ & $\begin{array}{c}\text { Molarity } \\
(\mathrm{M})\end{array}$ \\
\hline No Reaction & 0 & 0.5 & 4 & 0.1 \\
Slight Reaction & 1 & 0.5 & 8 & 0.1 \\
Moderate Reaction & 2 & 0.5 & 20 & 0.5 \\
Strong Reaction & 3 & 0.5 & 40 & 0.5 \\
Very strong reaction & 4 & 1.0 & 40 & 0.5 \\
& $5^{*}$ & 1.0 & 60 & 0.5 \\
\hline
\end{tabular}

*5 is used for very high ANC material $\left(>400 \mathrm{kgH}_{2} \mathrm{SO}_{4} / \mathrm{t}\right)$ e.g. limestone

$\mathrm{ANC}$ 를 반복적으로 수행하여 적당한 염산 투입량을 결 정하는 과정이 필요하다. 투입된 염산을 시료와 반응시 킬 때 반응속도를 향상시키기 위해서 혼탁액의 온도를 약 $80 \sim 90^{\circ} \mathrm{C}$ 로 설정하여 반응이 종료될 때까지(더이상 기 체가 발생하지 않아 입자들이 바닥에 완전히 가라앉은 상태) 유지하되 최소 2 시간은 가열해야 하며 간간이 용 액을 흔들어주고 증발된 물을 채워 일정한 부피를 유지 해야 한다. 반응이 완료된 혼탁액은 온도를 상온으로 낮 춘 후 $\mathrm{pH}$ 를 측정하여 염산 투입량의 적정성을 확인한다. 시료와 반응하지 않고 남아있는 산의 양은 Fizz 시험에 서 결정된 수산화나트륨을 이용해 $\mathrm{pH}$ 7까지 역적정(back titration)을 통해 도출한다. 투입된 산의 양과 소모되지 않 은 산의 차를 구하면 시료와 반응한 산 소모량을 계산할 수 있고 단위환산을 통해 산중화능을 구할 수 있다. 다 만, 적정하는 과정에서 $\mathrm{pH}$ 5에 도달한 혼탁액에 $30 \%$ 과 산화수소 2 방울을 투입한 후 약 5 분 동안 반응시켜 혼탁 액의 산화반응을 유지한다. 이 과정을 통해 혼탁액 내에 존재하는 $\mathrm{Fe}^{2+}$ 의 산화를 촉진시켜 산중화능이 과대평가 되는 것을 최소화 할 수 있다(KIGAM, 2014).

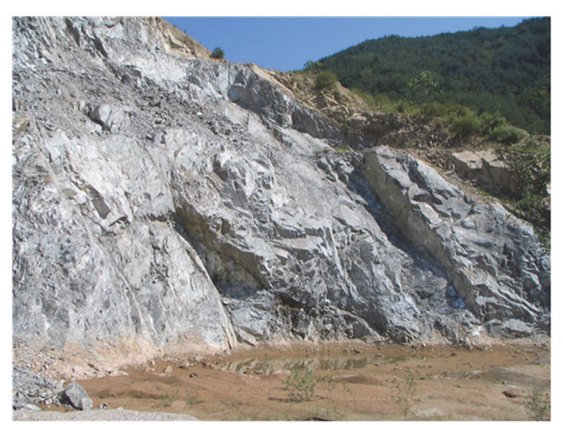

(a) On-site sampling

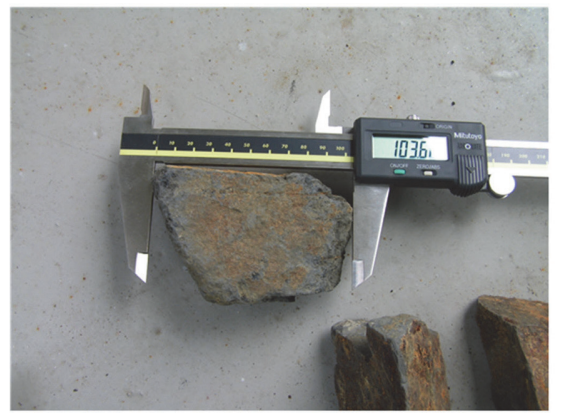

(b) Sample characterization

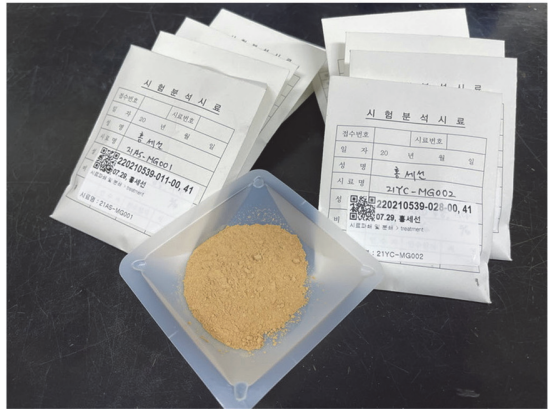

(c) Crushing $(<75 \mu \mathrm{m})$

Fig. 4. Pretreatment process through sampling and crushing(KIGAM, 2014). 


\subsection{NAG 시험}

$\mathrm{NAG}$ 시험은 강력한 산화제인 과산화수소를 시료와 반 응시켜 시료의 풍화를 빠른 시간내에 모사하는 시험이다. 투입된 과산화수소는 시료 내 산화 가능한 형태의 황화 광물과 반응하여 산발생능을 발현하게 되고 이렇게 발생된 산은 동시에 시료 내 산중화능을 발현하는 광물과 반응하 게 된다. NAG 시험은 이론적으로 최대 산발생능과 최대 산중화능을 도출하는 $\mathrm{ABA}$ 와 달리 과산화수소와의 반응 내 에서 발현 가능한 산발생량을 고려한다. NAG 시험은 과산 화수소를 이용해 잠재적으로 산발생능을 가진 광물을 강제 산화시키는 과정이므로 $\mathrm{NAG}$ 시험을 통해 계산되는 산 발생량은 시료의 산중화능이 부족하면 양수, 산중화능이 충분히 발현되어 산발생능과 모두 반응하면 0이 되며 직접 적으로 산중화능의 총량을 구할 순 없다. 다만 반응용액의 $\mathrm{pH}(\mathrm{NAGpH})$ 를 측정하면 간접적으로 이를 평가할 수 있 다. $\mathrm{NAGpH}$ 는 4.5 를 기준으로 그 이하이면 산을 발생하 는 시료, 그 이상이면 산을 발생하지 않는 시료로 간주한다.

$\mathrm{NAG}$ 시험은 전처리된 시료 $2.5 \mathrm{~g}$ 과 $15 \%$ 과산화수소 $250 \mathrm{ml}$ 을 반응시키는 것으로 시작한다. 과산화수소와 시 료의 혼탁액에서 증발하여 손실되는 것을 최소화하기 위 해 유리접시로 반응용기를 덮어준다. 혼탁액은 반응이 종 료될 때 (기포생성 중단 및 시료침전)까지 방치시키며 경 우에 따라 24시간 이상 소요될 수 있다. 시험이 진행되 는 과정에 간간이 혼탁액을 교반하거나 증류수를 채워 일정한 시험조건을 유지해야 한다. 반응시작 후 황화광 물 함량이 높아 과산화수소와 반응이 활발한 경우 황화 광물 함량이 낮은 경우에 비해 반응이 일찍 종료된다. 반 응이 종료된 혼탁액은 가열판을 이용해 $80 \sim 90^{\circ} \mathrm{C}$ 에서 최 소 2 시간이상 유지하여 잔여 황화광물의 반응을 촉진시 키는 동시에 혼탁액 내 남아있는 잉여 과산화수소를 분 해시킨다. 혼탁액 내 잉여 과산화수소는 산발생량 측정 시 영향을 끼치므로 반드시 제거해야 한다. 반응이 종료 되면 증류수를 이용해 용기 벽면에 묻은 혼탁액을 헹궈 내고 최종부피를 $250 \mathrm{ml}$ 로 맞춘다. 시험이 종료된 혼탁 액을 상온으로 식힌 후 $\mathrm{pH}$ 를 측정한다(KIGAM, 2014).

\section{4. 결 과}

연구대상 지역 시료 들의 XRD 분석 결과를 보면 칼슘 을 포함하고 있는 중화 물질들이 존재하는 광물이 있음 을 확인하였고 또한 황철석 등의 산발생 능력이 있는 광 물의 조성도 확인 할 수 있었다(Table 2). 산성암석배수 를 발생시키는 원인으로 황철석은 산성암석배수 발생의 주요인으로 인지되고 있다. 이 밖에도 자류철석(pyrrohotite), 백철석(marcasite), 황동석(chalcopyrite), 유비철석(asenopyrite)
과 같은 황화광물이 지표에 노출되어 산을 생성시켜 주변 자연수의 $\mathrm{pH}$ 를 낮추고 $\mathrm{Al}, \mathrm{Mn}, \mathrm{Zn}, \mathrm{Cd}$ 및 $\mathrm{Pb}$ 등의 용출로 인해 중금속이 함유된 산성암석배수가 생성될 수 있다. 지층의 총 황 함량이 $1 \%$ 이상 함유할 때 상당한 수질오 염이 예상된다고 보고된 바도 있다(Younger et al., 2002).

산발생능을 평가하기 위해 NAPP와 $\mathrm{NAG} \mathrm{pH}$ 값을 계 산하여 Fig. 5에 도시하였다. NAPP의 단위는 단위 암석 의 무게당 발생하는 황산의 무게를 의미하며 연구 대상 지역의 산림골재를 평가한 암석 시료의 경우 대부분이 산을 중화시키는 물질이 발생하는 것으로 확인되었다. 시 험에서 산중화능을 발현한 광물은 일부 백운모 광물인 것으로 판단되는데 이는 실제 자연환경에서 쉽게 중화능 을 발현하지 못하는 것으로 알려져 있으므로 중화능 값 은 정량적인 데이터로 활용할 수 없을 것으로 판단된다 (Table 3). 산발생 평가를 위해 분석된 연구 대상지역의 시료들은 전체적으로 황함량이 높을수록 발생 가능한 황 산 $\left(\mathrm{H}_{2} \mathrm{SO}_{4}\right)$ 양이 많은 경향을 보였다.

가평군의 대부분의 시료는 낮은 황함량을 보여 $\mathrm{ARD}$ 발생 가능성이 낮은 것으로 나타났으며, 암석이 산을 중 화할 수 있는 잠재력을 나타내는 산중화능 수치가 ARD 발생가능성 수치보다 높아 산성암석배수 유발 가능성이 작다고 판단된다. NAG 시험에서 대부분의 시료는 산비 발생(NAF)으로 분류되었다.

광주시 시료의 MG02는 다른 시료에 비해 상당히 높은 황 함량을 보이고 $\mathrm{MG} 06, \mathrm{M} 01$ 과 함께 산발생 $(\mathrm{PAF})$ 으로 분 류되었다. 그러나 대부분의 시료는 낮은 황함량을 보여 $\mathrm{ARD}$ 발생 가능성이 낮은 것으로 나타났으며, ANC 시험 에서 $\mathrm{MG} 03, \mathrm{CG} 03, \mathrm{CG} 05$ 시료의 경우 산중화능이 약 $33 \sim 53 \mathrm{~kg} \mathrm{H}_{2} \mathrm{SO}_{4} / \mathrm{t}$ 으로 높게 나타나 다른 시료에 비해 탄 산염광물의 함유량이 높은 것으로 유추할 수 있다. 암석 이 산을 중화할 수 있는 잠재력을 나타내는 산중화능 수 치가 ARD 발생가능성 수치보다 높아 산성암석배수 유 발 가능성이 낮다고 판단된다. NAG 시험에서 $\mathrm{MG} 02$, $\mathrm{MG} 06, \mathrm{M} 01$ 을 제외하고 대부분의 시료는 산비발생(NAF) 으로 분류되었다.

고양시의 대부분의 시료는 낮은 황함량을 보여 $\mathrm{ARD}$ 발생 가능성이 낮은 것으로 나타났으며, $\mathrm{ANC}$ 시험에서 $\mathrm{CG} 01, \mathrm{CG} 02, \mathrm{CG} 04$ 시료의 경우 산중화능이 약 $48 \sim 60 \mathrm{~kg}$ $\mathrm{H}_{2} \mathrm{SO}_{4} / \mathrm{t}$ 으로 높게 나타나 다른 시료에 비해 탄산염광물의 함유량이 높은 것으로 유추할 수 있다. NAG 시험에서 $\mathrm{MG} 002, \mathrm{M} 01$ 을 제외하고 대부분의 시료는 산비발생(NAF) 으로 분류되었다. M01은 황함량과 산발생능이 높고 MG02 와 함께 산성암석배수 발생 가능성이 크다고 판단된다.

괴산군의 대부분의 시료는 낮은 황함량을 보여 $\mathrm{ARD}$ 발생 가능성이 낮은 것으로 나타났으며, $\mathrm{ANC}$ 시험에서 
$\mathrm{MG10,} \mathrm{MG13,} \mathrm{MG17,} \mathrm{M} 02$ 시료의 경우 산중화능이 약 $33 \sim 78 \mathrm{~kg} \mathrm{H}_{2} \mathrm{SO}_{4} / \mathrm{t}$ 으로 높게 나타나 다른 시료에 비해 탄 산염광물의 함유량이 높은 것으로 유추할 수 있다. NAG 시험에서 대부분의 시료는 산비발생(NAF)으로 분류되었다. 속초시 시료의 MG06은 높은 황함량을 보이고 MG01, $\mathrm{MG} 03$ 시료와 같이 산성암석배수 발생 가능성이 높다고
판단되었다. 그 외의 시료는 낮은 황함량을 보여 $\mathrm{ARD}$ 발생 가능성이 낮은 것으로 나타났다. NAG 시험에서 $\mathrm{MG} 01, \mathrm{MG} 02, \mathrm{MG} 06$ 은 산발생(PAF)로 나머지 시료는 산 비발생 $(\mathrm{NAF})$ 으로 분류되었다. 이들 시료는 $\mathrm{XRD}$ 분석에 서 백운모가 없거나 작게 나온 것으로 분석되었다(Table 2). 합천시의 분석된 모든 시료는 낮은 황함량을 보여 $\mathrm{ARD}$

Table 2. Mineral composition according to XRD analysis of the samples

\begin{tabular}{|c|c|}
\hline Sample & Mineral composition \\
\hline Gapyeong-gun-MG01 & Plagioclase, Quartz, K-feldspar, Muscovite, Chlorite, Biotite \\
\hline Gapyeong-gun-MG02 & Plagioclase, Quartz, K-feldspar, Muscovite, Chlorite \\
\hline Gapyeong-gun-MG03 & Plagioclase, Quartz, K-feldspar, Muscovite, Chlorite, Hematite, Diopside \\
\hline Gapyeong-gun-MG04 & Plagioclase, Quartz, K-feldspar, Muscovite, Biotite \\
\hline Gapyeong-gun-MG05 & Plagioclase, Quartz, K-feldspar, Chlorite, Calcite, Diopside, Hornblende, Biotite \\
\hline Gapyeong-gun-MG06 & Plagioclase, Quartz, Muscovite, Chlorite, Hematite, Biotite \\
\hline Gapyeong-gun-MG07 & Plagioclase, Quartz, K-feldspar, Muscovite, Chlorite, Biotite \\
\hline Gapyeong-gun-MG08 & Plagioclase, Quartz, K-feldspar, Muscovite, Chlorite \\
\hline Gapyeong-gun-MG09 & Plagioclase, Quartz, Muscovite, Biotite \\
\hline Gapyeong-gun-MG10 & Plagioclase, Quartz, K-feldspar, Muscovite, Chlorite \\
\hline Gapyeong-gun-MG11 & Plagioclase, Quartz, K-feldspar, Muscovite, Chlorite, Hematite \\
\hline Gapyeong-gun-CG01 & Plagioclase, Quartz, K-feldspar, Muscovite, Chlorite \\
\hline Gapyeong-gun-CG02 & Plagioclase, Quartz, K-feldspar, Muscovite, Chlorite, Biotite \\
\hline Gapyeong-gun-CG03 & Plagioclase, Quartz, K-feldspar, Muscovite, Chlorite, Hornblende, Biotite \\
\hline Gapyeong-gun-M01 & Plagioclase, Quartz, K-feldspar, Chlorite, Hornblende, Biotite \\
\hline Gapyeong-gun-M02 & Plagioclase, Quartz, Muscovite, Chlorite, Biotite, Pyrite \\
\hline Gwangju-si-MG01 & Plagioclase, Quartz, K-feldspar, Muscovite, Chlorite, Hornblende, Biotite, Pyrite \\
\hline Gwangju-si-MG02 & Plagioclase, Quartz, K-feldspar, Muscovite, Chlorite \\
\hline Gwangju-si-MG03 & Plagioclase, Quartz, K-feldspar, Muscovite, Chlorite, Calcite, Biotite \\
\hline Gwangju-si-MG04 & Plagioclase, Quartz, Muscovite, Chlorite, Biotite \\
\hline Gwangju-si-MG05 & Plagioclase, Quartz, K-feldspar, Muscovite, Chlorite, Hornblende, Biotite \\
\hline Gwangju-si-MG06 & Plagioclase, Quartz, K-feldspar, Muscovite, Chlorite. Biotite \\
\hline Gwangju-si-MG07 & Plagioclase, Quartz, K-feldspar, Muscovite, Biotite \\
\hline Gwangju-si-MG08 & Plagioclase, Quartz, K-feldspar, Biotite \\
\hline Gwangju-si-MG09 & Plagioclase, Quartz, K-feldspar, Muscovite, Chlorite, Biotite \\
\hline Gwangju-si-CG01 & Plagioclase, Quartz, K-feldspar, Chlorite, Hornblende, Biotite \\
\hline Gwangju-si-CG02 & Plagioclase, Quartz, K-feldspar, Muscovite, Chlorite, Hornblende, Biotite \\
\hline Gwangju-si-CG03 & Plagioclase, Quartz, K-feldspar, Muscovite, Chlorite, Hornblende, Biotite \\
\hline Gwangju-si-CG04 & Plagioclase, Quartz, K-feldspar, Muscovite, Chlorite \\
\hline Gwangju-si-CG05 & Plagioclase, Quartz, K-feldspar, Muscovite, Chlorite, Hornblende, Biotite \\
\hline Gwangju-si-M01 & Plagioclase, Quartz, Muscovite, Chlorite, Biotite \\
\hline Goyang-si-MG01 & Plagioclase, Quartz, K-feldspar, Muscovite \\
\hline Goyang-si-MG02 & Plagioclase, Quartz, K-feldspar, Muscovite, Biotite \\
\hline Goyang-si-MG03 & Plagioclase, Quartz, K-feldspar, Muscovite, Biotite \\
\hline Goyang-si-CG01 & Plagioclase, Quartz, K-feldspar, Muscovite, Chlorite, Calcite \\
\hline Goyang-si-CG02 & Plagioclase, Quartz, K-feldspar, Muscovite, Chlorite, Calcite, Biotite \\
\hline Goyang-si-CG03 & Plagioclase, Quartz, K-feldspar, Muscovite, Chlorite, Biotite \\
\hline Goyang-si-CG04 & Plagioclase, Quartz, K-feldspar, Muscovite, Chlorite, Calcite, Biotite \\
\hline Goyang-si-CG05 & Plagioclase, Quartz, K-feldspar, Muscovite, Chlorite, Calcite, Hornblende, Biotite \\
\hline Goyang-si-CG06 & Plagioclase, Quartz, K-feldspar, Muscovite, Chlorite, Hornblende, Biotite \\
\hline Goyang-si-CG07 & Plagioclase, Quartz, K-feldspar, Muscovite, Chlorite, Calcite \\
\hline Goyang-si-M01 & Plagioclase, Quartz, Muscovite, Chlorite, Biotite, Pyrite \\
\hline
\end{tabular}


Table 2. Continued

\begin{tabular}{|c|c|}
\hline Sample & Mineral composition \\
\hline Goesan-gun-MG01 & Plagioclase, Quartz, K-feldspar, Muscovite, Chlorite, Calcite \\
\hline Goesan-gun-MG02 & Plagioclase, Quartz, K-feldspar, Muscovite, Chlorite, Magnetite \\
\hline Goesan-gun-MG03 & Plagioclase, Quartz, K-feldspar, Muscovite, Chlorite, Hematite \\
\hline Goesan-gun-MG04 & Quartz, Muscovite, Chlorite, Calcite, Diopside, Hornblende, Biotite \\
\hline Goesan-gun-MG05 & Plagioclase, Quartz, K-feldspar, Muscovite, Chlorite, Calcite, Biotite \\
\hline Goesan-gun-MG06 & Plagioclase, Quartz, K-feldspar, Muscovite, Chlorite, Calcite, Biotite \\
\hline Goesan-gun-MG07 & Plagioclase, Quartz, K-feldspar, Muscovite, Chlorite \\
\hline Goesan-gun-MG08 & Plagioclase, Quartz, K-feldspar, Muscovite, Biotite \\
\hline Goesan-gun-MG09 & Plagioclase, Quartz, K-feldspar, Chlorite, Calcite, Diopside, Hornblende \\
\hline Goesan-gun-MG10 & Plagioclase, Quartz, K-feldspar, Muscovite, Calcite, Hematite, Diopside, Talc \\
\hline Goesan-gun-MG11 & Plagioclase, Quartz, K-feldspar, Muscovite, Chlorite, Calcite, Diopside, Hornblende \\
\hline Goesan-gun-MG12 & Plagioclase, Quartz, K-feldspar, Muscovite, Chlorite, Calcite, Hornblende, Biotite \\
\hline Goesan-gun-MG13 & Plagioclase, Quartz, Muscovite, Chlorite, Calcite, Biotite, 백운석 \\
\hline Goesan-gun-MG14 & Plagioclase, Quartz, K-feldspar, Muscovite, Chlorite, Calcite, Hornblende \\
\hline Goesan-gun-MG15 & Plagioclase, Quartz, K-feldspar, Muscovite, Chlorite, Calcite, Biotite \\
\hline Goesan-gun-MG16 & Plagioclase, Quartz, K-feldspar, Chlorite, Calcite, Hornblende, Biotite \\
\hline Goesan-gun-MG17 & Plagioclase, Quartz, K-feldspar, Chlorite, Calcite, Diopside, Hornblende \\
\hline Goesan-gun-M001 & Plagioclase, Quartz, K-feldspar, Muscovite, Chlorite, Calcite, Biotite \\
\hline Goesan-gun-M002 & Plagioclase, Quartz, Muscovite, Chlorite, Calcite \\
\hline Sokcho-si-MG01 & Plagioclase, Quartz, K-feldspar \\
\hline Sokcho-si-MG02 & Plagioclase, Quartz, Muscovite, Chlorite, Biotite \\
\hline Sokcho-si-MG03 & Plagioclase, Quartz, K-feldspar, Muscovite \\
\hline Sokcho-si-MG04 & Plagioclase, Quartz, K-feldspar, Muscovite, Chlorite, Hornblende, Biotite \\
\hline Sokcho-si-MG05 & Plagioclase, Quartz, K-feldspar, Muscovite, Chlorite, Hornblende \\
\hline Sokcho-si-MG06 & Plagioclase, Quartz, K-feldspar, Biotite \\
\hline Sokcho-si-MG07 & Plagioclase, Quartz, K-feldspar, Muscovite, Chlorite \\
\hline Hapcheon-gun-MG01 & Plagioclase, Quartz, Muscovite, Chlorite, Calcite, Hornblende \\
\hline Hapcheon-gun-MG02 & Plagioclase, Quartz, K-feldspar, Muscovite, Chlorite, Hematite, \\
\hline Hapcheon-gun-MG03 & Plagioclase, Quartz, K-feldspar, Muscovite, Hornblende \\
\hline Hapcheon-gun-MG04 & Plagioclase, Quartz, K-feldspar, Muscovite, Chlorite \\
\hline Hapcheon-gun-MG05 & Plagioclase, Quartz, K-feldspar, Muscovite, Biotite \\
\hline Hapcheon-gun-MG06 & Plagioclase, Quartz, Muscovite, Chlorite, Calcite \\
\hline Hapcheon-gun-MG07 & Plagioclase, Quartz, Muscovite, Chlorite, Calcite \\
\hline Hapcheon-gun-MG08 & Plagioclase, Quartz, K-feldspar, Muscovite, Chlorite, Calcite \\
\hline Hapcheon-gun-MG09 & Plagioclase, Quartz, K-feldspar, Muscovite, Chlorite, Calcite \\
\hline Hapcheon-gun-MG10 & Plagioclase, Quartz, Muscovite, Chlorite, Calcite \\
\hline Hapcheon-gun-MG11 & Plagioclase, Quartz, Muscovite, Calcite \\
\hline Hapcheon-gun-MG12 & Plagioclase, Quartz, K-feldspar, Muscovite, Chlorite, Calcite, Hematite \\
\hline Hapcheon-gun-MG13 & Plagioclase, Quartz, K-feldspar, Muscovite, Magnetite, Hornblende \\
\hline Hapcheon-gun-MG14 & Plagioclase, Quartz, K-feldspar, Muscovite, Chlorite, Magnetite, Hornblende \\
\hline Hapcheon-gun-MG15 & Plagioclase, Quartz, K-feldspar, Muscovite, Chlorite, Hornblende \\
\hline Hapcheon-gun-MG16 & Plagioclase, Quartz, K-feldspar, Muscovite, Magnetite, Hornblende \\
\hline Hapcheon-gun-MG17 & Plagioclase, Quartz, K-feldspar, Muscovite, Chlorite, Calcite \\
\hline Hapcheon-gun-MG18 & Plagioclase, Quartz, Muscovite, Chlorite, Calcite, Dolomite \\
\hline Hapcheon-gun-MG19 & Plagioclase, Quartz, K-feldspar, Muscovite \\
\hline Hapcheon-gun-MG20 & Plagioclase, Quartz, K-feldspar, Muscovite, Chlorite, Calcite \\
\hline Hapcheon-gun-MG21 & Plagioclase, Quartz, K-feldspar, Muscovite, Chlorite, Calcite \\
\hline Hapcheon-gun-MG22 & Plagioclase, Quartz, K-feldspar, Muscovite, Chlorite, Hornblende, Biotite \\
\hline Hapcheon-gun-MG23 & Plagioclase, Quartz, Chlorite, Magnetite, Hornblende \\
\hline Hapcheon-gun-M01 & Plagioclase, Quartz, K-feldspar, Chlorite, Calcite, Hornblende \\
\hline Hapcheon-gun-M02 & Plagioclase, Quartz, K-feldspar, Chlorite, Calcite, Hematite \\
\hline
\end{tabular}


발생 가능성이 낮은것으로 나타났으며, $\mathrm{ANC}$ 시험에서 MG07, MG08, MG10, MG11, MG12, MG17, MG18, M01 시료의 경우 산중화능이 약 $55 \sim 90 \mathrm{~kg} \mathrm{H}_{2} \mathrm{SO}_{4} / \mathrm{t}$ 으로 높게
나타나 다른 시료에 비해 탄산염광물의 함유량이 높은 것으로 유추할 수 있다. 암석이 산을 중화할 수 있는 잠 재력을 나타내는 산중화능 수치가 ARD 발생가능성 수

Table 3. S (\%), MPA (kg H2SO4/t) and ANC (kg H2SO4/t) test results of the samples

\begin{tabular}{|c|c|c|c|c|c|c|c|}
\hline Sample & Total S & MPA & ANC & Sample & Total S & MPA & $\mathrm{ANC}$ \\
\hline Gapyeong-gun-MG01 & 0.21 & 6.49 & 6.79 & Goesan-gun-MG06 & 0.08 & 2.30 & 23.48 \\
\hline Gapyeong-gun-MG02 & 0.06 & 1.71 & 0.26 & Goesan-gun-MG07 & 0.04 & 1.13 & -0.79 \\
\hline Gapyeong-gun-MG03 & 0.07 & 2.20 & 2.71 & Goesan-gun-MG08 & 0.03 & 0.89 & 1.06 \\
\hline Gapyeong-gun-MG04 & 0.01 & 0.21 & 6.88 & Goesan-gun-MG09 & 0.20 & 6.24 & 11.27 \\
\hline Gapyeong-gun-MG05 & 0.07 & 2.17 & 31.22 & Goesan-gun-MG10 & 0.33 & 10.13 & 39.60 \\
\hline Gapyeong-gun-MG06 & 0.01 & 0.31 & 9.79 & Goesan-gun-MG11 & 0.11 & 3.46 & 22.25 \\
\hline Gapyeong-gun-MG07 & 0.01 & 0.34 & 6.61 & Goesan-gun-MG12 & 0.05 & 1.53 & 6.26 \\
\hline Gapyeong-gun-MG08 & 0.01 & 0.37 & 9.50 & Goesan-gun-MG13 & 0.58 & 17.60 & 54.44 \\
\hline Gapyeong-gun-MG09 & 0.11 & 3.43 & 7.14 & Goesan-gun-MG14 & 0.05 & 1.65 & 11.27 \\
\hline Gapyeong-gun-MG10 & 0.24 & 7.47 & 23.51 & Goesan-gun-MG15 & 0.03 & 0.98 & 0.79 \\
\hline Gapyeong-gun-MG11 & 0.12 & 3.79 & 0.26 & Goesan-gun-MG16 & 0.06 & 1.87 & 5.01 \\
\hline Gapyeong-gun-CG01 & 0.13 & 4.04 & 1.06 & Goesan-gun-MG17 & 0.04 & 1.07 & 64.47 \\
\hline Gapyeong-gun-CG02 & 0.12 & 3.52 & 5.43 & Goesan-gun-M001 & 0.14 & 4.31 & 33.42 \\
\hline Gapyeong-gun-CG03 & 0.15 & 4.59 & 9.52 & Goesan-gun-M002 & 0.15 & 4.59 & 77.96 \\
\hline Gapyeong-gun-M01 & 0.15 & 4.56 & 20.63 & Sokcho-si-MG01 & 0.15 & 4.59 & 0.00 \\
\hline Gapyeong-gun-M02 & 0.14 & 4.22 & 12.21 & Sokcho-si-MG02 & 0.14 & 4.35 & 1.32 \\
\hline Gwangju-si-MG01 & 0.19 & 5.81 & 7.14 & Sokcho-si-MG03 & 0.13 & 3.98 & 0.00 \\
\hline Gwangju-si-MG02 & 0.68 & 20.66 & 2.91 & Sokcho-si-MG04 & 0.02 & 0.61 & 1.85 \\
\hline Gwangju-si-MG03 & 0.39 & 11.93 & 49.46 & Sokcho-si-MG05 & 0.02 & 0.55 & 5.28 \\
\hline Gwangju-si-MG04 & 0.39 & 12.00 & 5.56 & Sokcho-si-MG06 & 0.26 & 8.08 & 0.26 \\
\hline Gwangju-si-MG05 & 0.26 & 7.99 & 7.40 & Sokcho-si-MG07 & 0.13 & 3.95 & 2.91 \\
\hline Gwangju-si-MG06 & 0.21 & 6.55 & 0.26 & Hapcheon-gun-MG01 & 0.04 & 1.10 & 7.53 \\
\hline Gwangju-si-MG07 & 0.15 & 4.56 & 4.08 & Hapcheon-gun-MG02 & 0.03 & 0.80 & 6.27 \\
\hline Gwangju-si-MG08 & 0.33 & 10.13 & 6.07 & Hapcheon-gun-MG03 & 0.02 & 0.67 & 1.32 \\
\hline Gwangju-si-MG09 & 0.16 & 4.99 & 2.90 & Hapcheon-gun-MG04 & 0.03 & 0.89 & 8.15 \\
\hline Gwangju-si-CG01 & 0.11 & 3.21 & 23.48 & Hapcheon-gun-MG05 & 0.09 & 2.82 & 12.16 \\
\hline Gwangju-si-CG02 & 0.13 & 4.07 & 5.43 & Hapcheon-gun-MG06 & 0.08 & 2.30 & 22.99 \\
\hline Gwangju-si-CG03 & 0.10 & 3.00 & 33.41 & Hapcheon-gun-MG07 & 0.04 & 1.35 & 72.96 \\
\hline Gwangju-si-CG04 & 0.08 & 2.48 & 5.55 & Hapcheon-gun-MG08 & 0.04 & 1.32 & 55.77 \\
\hline Gwangju-si-CG05 & 0.26 & 7.83 & 53.21 & Hapcheon-gun-MG09 & 0.03 & 1.04 & 38.36 \\
\hline Gwangju-si-M01 & 0.13 & 3.83 & 2.72 & Hapcheon-gun-MG10 & 0.04 & 1.29 & 83.03 \\
\hline Goyang-si-MG01 & 0.12 & 3.73 & 0.26 & Hapcheon-gun-MG11 & 0.02 & 0.64 & 85.49 \\
\hline Goyang-si-MG02 & 0.10 & 3.00 & 0.26 & Hapcheon-gun-MG12 & 0.02 & 0.49 & 90.29 \\
\hline Goyang-si-MG03 & 0.12 & 3.79 & 4.49 & Hapcheon-gun-MG13 & 0.14 & 4.31 & 9.49 \\
\hline Goyang-si-CG01 & 0.11 & 3.46 & 49.58 & Hapcheon-gun-MG14 & 0.11 & 3.34 & 13.58 \\
\hline Goyang-si-CG02 & 0.13 & 4.01 & 56.92 & Hapcheon-gun-MG15 & 0.12 & 3.76 & 3.96 \\
\hline Goyang-si-CG03 & 0.13 & 4.01 & 9.52 & Hapcheon-gun-MG16 & 0.09 & 2.63 & 10.04 \\
\hline Goyang-si-CG04 & 0.13 & 3.83 & 48.32 & Hapcheon-gun-MG17 & 0.07 & 2.11 & 64.35 \\
\hline Goyang-si-CG05 & 0.13 & 4.07 & 12.21 & Hapcheon-gun-MG18 & 0.07 & 2.20 & 90.33 \\
\hline Goyang-si-CG06 & 0.12 & 3.79 & 8.14 & Hapcheon-gun-MG19 & 0.09 & 2.88 & 1.36 \\
\hline Goyang-si-CG07 & 0.11 & 3.34 & 51.97 & Hapcheon-gun-MG20 & 0.08 & 2.39 & 45.78 \\
\hline Goyang-si-M01 & 0.31 & 9.49 & 4.07 & Hapcheon-gun-MG21 & 0.08 & 2.51 & 25.99 \\
\hline Goesan-gun-MG01 & 0.21 & 6.52 & 3.71 & Hapcheon-gun-MG22 & 0.07 & 2.11 & 13.74 \\
\hline Goesan-gun-MG02 & 0.04 & 1.32 & 8.79 & Hapcheon-gun-MG23 & 0.12 & 3.76 & 12.42 \\
\hline Goesan-gun-MG03 & 0.03 & 0.80 & -1.26 & Hapcheon-gun-M01 & 0.10 & 3.09 & 73.01 \\
\hline Goesan-gun-MG04 & 0.17 & 5.17 & 22.31 & Hapcheon-gun-M02 & 0.10 & 2.91 & 12.22 \\
\hline Goesan-gun-MG05 & 0.05 & 1.56 & 0.00 & & & & \\
\hline
\end{tabular}


치보다 높아 산성암석배수 유발 가능성이 낮다고 판단된 다. 대부분의 시료는 산비발생(NAF)으로 분류되었다.

최근 연구에 따르면 본 연구에서 수행된 시험법이 풍
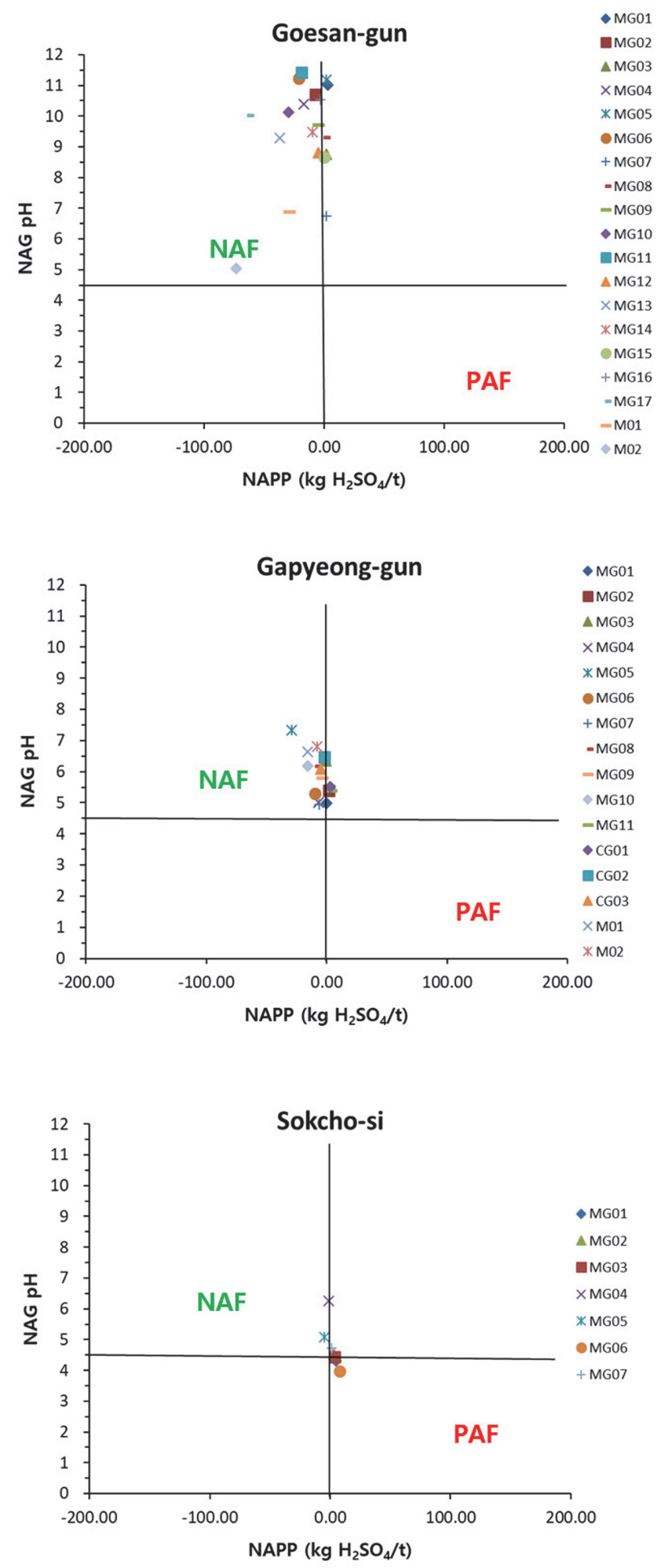

화가 많이 진행된 황을 포함하는 시료와 같은 특정 상황 에서 오차가 커진다는 보고가 있었으나 연구 대상 노두 시료의 경우 풍화가 진행되지 않은 노두를 대상으로 하
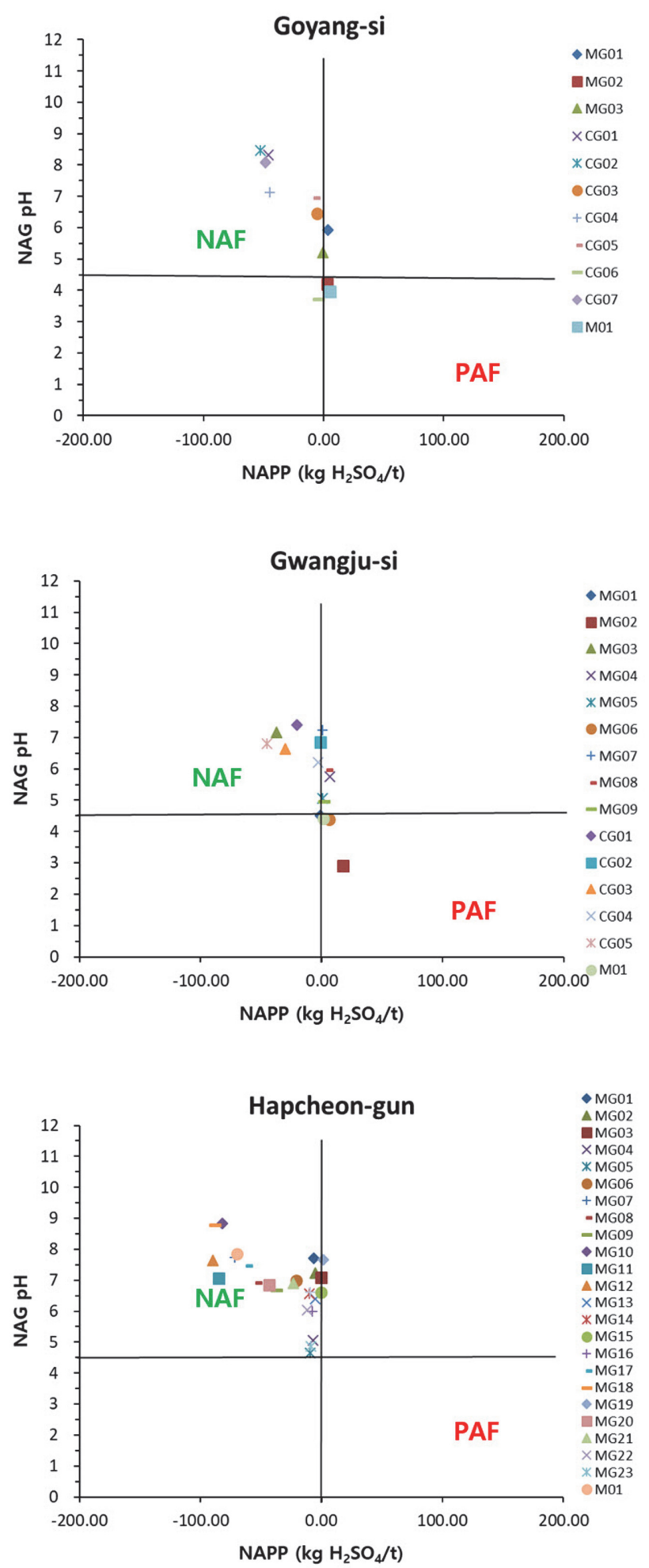

Fig. 5. Results of the acid-forming potential evaluation of the samples. 
였으므로 그러한 오차가 내재할 가능성은 없을 것으로 판단되며 아래의 결과에 대한 신뢰도는 높은 편이라고 할 수 있다 (Oh et al., $2017 \mathrm{a}, \mathrm{b}$ ).

\section{5. 결 론}

골재의 개발이 국내의 많은 지역에서 발생되고 있다. 이때 개발부지가 황화광물이 수반된 지층일 경우 산성암 석배수(Acid Rock Drainage : ARD)가 발생하여 환경오 염 혹은 주변 구조물에 대한 부식 등의 문제를 발생시킬 수 있다. 어떤 지층의 잠재 산도(Potential acidity)는 지층 을 구성하는 구성광물에 우선적으로 지배되기 때문에 지 질 고유특성에 따라서 산 발생 가능성이 결정된다. 산성 암석배수를 발생시키는 원인으로 광물성분 중 황철석이 산성암석배수 발생의 주된 원인으로 인지되고 있다. 이 와같이 산발생 능력이 높은 광물 성분이 존재하거나 중 화능력이 상대적으로 낮은 암석에서 산성암석배수가 발 생할 수 있다고 예상된다.

가평군, 괴산군 및 합천군의 시험결과, $\mathrm{NAGpH}$ 는 모두 4.5 이상의 수치를 보여 산성암석배수를 유출시키지 않을 것이라는 예측을 간접적으로 확인할 수 있다.

광주시 시료에서 대부분은 산성암석배수 발생 가능성 은 낮은 것으로 판단되지만, 시료 3 개(MG02, MG06, M01) 에서 $\mathrm{ARD}$ 발생 가능성이 있는 것으로 나타났으며 불확 실(Uncertain) 5개(MG04, MG05, CG07, CG08, CG09) 시 료는 잠재적 산발생에는 포함되지 않았으나 산발생이 가 능할 수 있을 것으로 예상된다. 고양시 시료에서 대부분 은 산성암석배수 발생 가능성은 낮은 것으로 판단되지만, 시료 3개(MG02, CG06, M01)에서 $\mathrm{ARD}$ 발생 가능성이 있는 것으로 나타났으며 불확실(Uncertain) 2개(MG01, CG06) 시료는 잠재적 산발생에는 포함되지 않았으나 산 발생이 가능할 수 있을 것으로 예상된다. 속초시 시료에 서 대부분은 산성암석배수 발생 가능성은 낮은 것으로 판단되지만, 시료 3 개(MG01, MG03, MG06)에서 $\mathrm{ARD}$ 발생 가능성이 있는 것으로 나타났으며 불확실(Uncertain) 1 개(MG03) 시료는 잠재적 산발생에는 포함되지 않았으 나 산발생이 가능하다고 예상된다.

이상의 결과를 종합하여보면 광주시, 고양시, 속초시의 일부 시료에서 잠재적인 산발생 시료로 분류되어지는 결 과를 얻었다. 이는 향후 산발생 가능 지역에서 다량의 산 림골재가 채취될 경우 골재의 품질에 영향을 줄 수 있음 을 예상할 수 있다. 따라서 산림골재들을 채취시 산발생 가능 암석을 분류하여 별도로 관리하는 것이 필요할 것 으로 판단된다. 산발생이 가능한 골재가 포함된 골재는 장기적으로 구조물의 안정성과 환경오염을 초래할 수 있
어 이후 발생 될 수 있는 경제적 손실을 가져올 수 있다. 그러므로 산성암석배수 발생 예측을 통해 안전한 골재의 사용을 유도하는 것이 필요하다.

\section{사 사}

이 연구는 한국지질자원연구원에서 수행하고 있는 국 토교통부 “2021년 골재자원조사 및 관리사업(21-5205)" 의 일환으로 수행되었습니다.

\section{References}

AMIRA International (2002) ARD Test Handbook: Project P387A Prediction and Kinetic Control of Acid Mine Drainage, AMIRA International Limited, Melbourne, Australia.

Hammarstrom, J.M., Brady, K. and Cravotta, C.A. (2005) Acid-rock drainage at Skytop, Centre Country, Pensylvania 2004. USGS Open-File Report 2005-1148, p.44. doi: 10.3133/ofr20051148

Carrucio, F.T., Ferm, J.C., Horne, J., Geidel, G. and Baganz. B. (1977) Paleoenvironment of coal and its relation to drainage quality. USEPA Cincinati.

Gerson, A.R., Rolley, P.J., Davis, C., Feig, S.T., Doyle, S. and Smart, R.S.C. (2019) Unexpected Non-acid Drainage from Sulfidic Rock Waste. Sci. Rep., 9, 4357. doi: 10.1038/s41598019-40357-4

Kim, J.G., Lee, J.S. and Kim, T.K. (2008) Assessment of Acid Rock Drainage Production Potential and Damage Reduction Strategy: A Case Study of Tunnel Construction Area. Economic and Environmental Geology, v.41, no.3, p.335-344.

Korea institute of Geoscience and mineral resources(KIGAM) (2014) Investigation, analysis, and evaluation of geological environmental disasters according to mine development. Research Report, p.143.

Korea institute of Geoscience and mineral resources(KIGAM) (2019) Geologic map of KOREA(1:1,000,000)

Lee, G.H., Kim, J.G., Park, S.G., Lee, J.S., Chon, C.M. and Kim, T.H. (2005a) Damage Conditions and Assessment for Cut Slope Structures due to Acid Rock Drainage. Journal of the Korean Geotechnical Society, v.21, no.5, pp.83-92.

Lee, G.H., Kim, J.G., Lee, J.S., Chon, C.M., Park, S.G., Kim, T.H., Ko, G.S. and Kim, T.K. (2005b) Generation characteristics and prediction of acid rock drainage(ARD) of cut slope. Economic and Environmental Geology, v.38, no.1, p.91-99.

Lee, H.S., Ji, S.W., Ko, J.I., Kim, S.J. and Cheong, Y.W. (2006) A Study on the Assessment to Acid Rock Drainage Generation from Waste Rock Dumps of the Coal Mine. Journal of the Korean Society of Mineral and Energy Resources Engineers, v.43, no.5, p.523-531.

Ji, S.W. and Cheong, Y.W. (2005) Acid Generation and Corrosion Characteristics of Road-cut Rock and Mine Waste Rock. Journal of the Korean Society of Civil Engineers, v.25, no.4B, p.291300 . 
Ji, S.W., Cheong, Y.W., Yim, G.J. and Lee, H.S. (2006) An Evaluation of Acid Rock Drainage Generation at the Road Cut Slopes Exposed by Road Construction. Journal of the Korean Society of Mineral and Energy Resources Engineers, v.43, no.4, p.339-349.

Ji, S.W., Cheong, Y.W., Baek, S.H., Kim, Y.S., Ko, J.I., Kim, S.J., Yim, G.J. and Lee, H.S. (2007) Prediction of Acid Rock Drainage (ARD) Generation on Construction Sites and Its Application. Journal of the Korean Society of Mineral and Energy Resources Engineers, v.44, no.1, p.82-93.

Oh, C., Ji, S., Yim, G. and Cheong, Y. (2017a) Evaluation of net acid generation $\mathrm{pH}$ as a single indicator for acid forming potential of rocks using geochemical properties. Environmental Monitoring and Assessment, 2017, 189(4), 165, 14p. doi: 10.1007/s10661017-5869-7

Oh, C., Ji, S., Chon, C.-M., Yim, G. and Cheong, Y. (2017b) Reliability improvement for predicting acid-forming potential of rock samples using static tests. Environmental Monitoring and Assessment, 2017, 189(5), 207, 13p. doi: 10.1007/s10661-0175906-6

Orndorff, Z.W. (2001) Evaluation of Sulfidic Materials in Virginia Highway Corridors, Thesis for Ph.D. Dissertation, Virginia Polytechnic Institute and State University, virginia, USA, p.175
Orava, D. (1997) In-Pit Disposal for ARD Control, in Short Course Notes on Waste Rock Tailings Disposal Technologies for Reactive Waste Management, 4th. International Conference on Acid Rock Drainage, Vancouver, B.C. Canada

Sobek, A.A., Schuller, W.A., Freeman, J.R. and Smith, R.M. (1978) Field and Laboratory Methods Applicable to Overburdens and Minesoils, EPA-600/2- 78-054, USEPA

Sobek, A.A., Skousen, J.G. and Fisher, S.E. Jr. (2000) Chemical and Physical Properties of Overburdens and Minesoils. p.77-104 In: R.I. Barnhisel et al. (Eds.). Reclamation of Drastically Disturbed Lands. American Soc. Agron. Monograph No. 41, Madison WI.

USEPA and Hardrock Mining (2003) A Source Book for Industry in the Northwest and Alaska, Appendix C; Characterization of Ore, Waste Rock, and Tailings, C1-C17

Yim, G.J., Cheong, Y.W., Ji, S.W., Lee, H.S., Han, D.R. and Park, S.W. (2006) Prediction and Implication of Potential Acid Forming Rock in Some Parts of Gyeongnam Province, Korea. Journal of the Korean Society of Mineral and Energy Resources Engineers, v.43, no.4, p.350-358.

Younger, P.L., Banwart, S.A. and Hedin, R.S. (2002) Mine Water: Hydrology, Pollution, Remediation, Kluwer Academic Publishers, Dordrects, Netherlands, pp.442. 